\title{
ON-LINE SIMULATION OF BUILDING ENERGY PROCESSES: NEED AND RESEARCH REQUIREMENTS
}

\author{
Vineet R. Kamat \\ Civil and Environmental Engineering \\ University of Michigan \\ Ann Arbor, MI 48109, USA
}

\author{
Carol C. Menassa \\ Civil and Environmental Engineering \\ University of Michigan \\ Ann Arbor, MI 48109, USA
}

\author{
SangHyun Lee \\ Civil and Environmental Engineering \\ University of Michigan \\ Ann Arbor, MI 48109, USA
}

\begin{abstract}
Most building energy simulation software offers significant building energy performance capabilities; however, its use is limited to design phase only. There is significant benefit to have these energy simulation models available during operation phase for detection and diagnostics. Since simulation models and real building states are not coupled, the models are initialized in an empty state or run through a warm-up period (i.e., off-line simulation). This paper develops the need and research requirements for on-line simulation of building energy processes where current state variables obtained from sensors and meters in buildings are used to initialize the model. Based on the simulation results, a new corrective decision is made and implemented in the real process. This paper argues that on-line simulation can provide decision makers with reliable energy models to test different technical and behavioral interventions, and improve predictions of building performance, compared to the results obtained with existing off-line models.
\end{abstract}

\section{INTRODUCTION}

Despite significant advances in energy simulation software (e.g., eQuest 2009; EnergyPlus 2009a), energy management and control systems (EMCS) (EIA 2012; Goldman et al. 2010), and occupancy interventions (Abrahamse et al. 2005), buildings continue to be the number one consumers of energy in the United States (US). They use $40 \%$ of the nation's total primary energy and $70 \%$ of the generated electricity (EIA 2012; DOE 2010). The effects of this excessive energy use impact the economic well-being of the nation, contribute to reliance on foreign oil, and result in significant emissions of harmful greenhouse gases.

One important limitation of existing energy analysis and control systems is that they are highly decoupled (i.e., developed for a specific purpose and phase of the building life-cycle), which prevents their individual benefits from being collectively exploited to accurately predict, monitor, and improve energy efficiency in buildings (Pang et al. 2012). These tools require specific expertise (e.g., facility managers might be proficient in the use of EMCS but consider simulation models to be too complex), are time consuming, and rely heavily on availability and quality of data. Thus, as parallel advances in energy simulation, EMCS, and occupancy intervention methods continue to evolve, it is critical to extend their capabili- 
ties to allow their collective use for decision-making across different phases of the building life-cycle to improve building energy performance and reduce any adverse impacts.

This paper explores the need and research requirements of coupling energy simulation models with large-scale data collected from sensor systems in monitored buildings to enable on-line simulation of the building energy systems. The authors argue that enabling such coupling is necessary to build credible energy simulations that can model complex behaviors at the building-occupant-energy-controller interface.

\section{BACKGROUND AND SIGNIFICANCE}

The US has an estimated 5 million commercial buildings and 115 million residential households (EIA 2012; DOE 2010). However, rising energy costs and declining resources could soon render conditioned, comfortable and healthy indoor environments in these buildings unaffordable to many (DOE 2010). Thus, reducing energy demand of buildings during the operation phase is critical. This phase alone accounts for more than $80 \%$ of the total energy usage (UNEP-SBCI 2007).

Several alternatives are available to curtail wasteful energy use. First, older buildings can be retrofitted to reset building life, improve performance, and make energy use more predictable (Mora 2007). In newer buildings, energy consumption can be reduced by continuous monitoring and improvement of building performance through methods like energy management (e.g., Energy Star program (US EPA 2012)), and Fault Detection and Diagnosis (FDD) tools (e.g., Katipamula and Brambley 2005a and 2005b). These can be supplemented by interventions that target building occupants' perceptions towards energy consumption (Abrahamse et al. 2005). Despite these methods, buildings' actual energy consumption persistently exceeds that predicted in design phases anywhere from $30 \%$ to $100 \%$, due to several reasons (e.g., unpredictable weather conditions, equipment performance, faulty control strategies and unexpected occupancy behavior) (Menassa et al. 2012; Yudelson 2010; Dell'lsola and Kirk 2003; Soebarto and Williamson 2001).

\subsection{Significance}

Whether it is major retrofits for older buildings or energy management for newer buildings, technical solutions to reduce energy demand are abundantly available (Abraham and Nguyen 2004). These are supported by several fundamental process level components. For example, building codes and standards (i.e., IECC 2012 and ASHRAE 2010) provide minimum requirements for energy efficient design and construction. Energy simulation software (e.g., eQuest 2009; EnergyPlus 2009a), allow architects and engineers to develop detailed models that predict energy consumption during a building's operation phase, and select most efficient and economical technical solutions. On the other hand, energy management and control systems (EMCS) allow for continuous and systematic assessment and management of energy consumption during a building's operation phase, while respecting occupant health and comfort (Doukas et al. 2009; Capehart et al. 2003). They consist of both hardware (sensors, meters) and software components (control interface) (EIA 2012; Goldman et al. 2010; Andrews and Krogmann 2009a). Finally, occupancy intervention methods such as education, feedback, and rewards have been investigated in residential (Anderson et al. 2013; Peschiera and Taylor 2012; Abrahamse et al. 2005; Staats et al. 2004; Pickens 2002) and commercial buildings (Azar and Menassa 2012; Staats et al. 2000), with varying success. However, these disparate fundamental process level components are hard to integrate for problem solving and decision-making across different phases of the building life-cycle. Specifically:

1. The complexity of energy models developed by a design team of a new building limits the potential for their re-use in energy management during operation. Facility managers consider these models to be too specific and complex for operational decisions (Samuelson et al. 2011).

2. Energy models rely heavily on user data input, limiting their ability to simulate complex processes that need high-fidelity and real-time data, which in turn limits their usefulness to building managers investigating energy reduction alternatives (Menassa et al. 2013a). 
3. Several studies in literature report that when installed and used properly, EMCS can provide energy savings, occupancy comfort and safety at relatively low initial cost to building stakeholders (Široky'et al. 2011; Goldman et al. 2010; Jiang et al. 2009; Herrmann 2005); however, these savings cannot be quantified or guaranteed (Meier et al. 2011 and 2010).

4. Although some existing EMCS have intelligent FDD capabilities (Wu and Sun 2010; Lee et al. 2007; Schein et al. 2006; Katipamula and Brambley 2005a), facility managers still primarily use EMCS only for equipment control (Lowry 2002). They rely on their experience and go through trial periods to explore what technical solutions to building operations will work.

5. Most of the occupancy intervention approaches are experimental and based on limited data about occupancy energy use profiles, and often lead to limited energy savings and relapse after an intervention approach is halted (Peschiera et al. 2010; Abrahamse et al. 2005).

6. Building Information Modeling (BIM) has been used in literature to help provide building geometry, location and other data to initiate energy models (e.g., Kim and Anderson 2012). However, most of these models still rely on the experience of the modeler to provide initial information in BIM.

The above discussion emphasizes that design and operation phase tools for building simulation and energy management are highly de-coupled with the following primary technical limitations:

1. A single and monolithic model cannot simulate complex processes within a domain with the required fidelity and detail (e.g., the use of real data from EMCS can increase model accuracy)

2. A single set of model developers cannot have expert knowledge in all the details of a domain to be simulated (e.g., energy models account for occupancy schedules but not behaviors)

3. Individuals responsible for managing a building's energy systems generally do not have the training to utilize multiple models and systems that would allow such limitations to be overcome.

The most notable software that uses a modular middleware for coupling is the Building Controls Virtual Test Bed (BCVTB) developed at Lawrence Berkley National Laboratory (Pang et al. 2012; Wetter 2011). BCVTB uses Ptolemy II (Brooks et al. 2007) as a modular middleware to couple simulation programs. One of the limitations of BCVTB is that it integrates with a MATLAB/Simulink model through a specific interface, such as the Inter-Process Communication (IPC) and function calls (Wetter 2011). Thus, any two models executed using such an interface in one process are tightly coupled. More importantly, the coupled models still need to be initialized by the users.

This paper focuses on the first limitation listed above, and explores the coupling of real data from EMCS with energy simulation models in order to increase model accuracy and credibility. The authors have recently developed and tested a conceptual framework for an energy simulation federation in an IEEE 1516 High Level Architecture (HLA) compliant environment (Menassa et al. 2013a). We coupled a DOE 2 energy model with an agent-based model (ABM) of building occupants developed by Azar and Menassa (2012) that simulates changes in their behaviors due to feedback. The DOE 2 and ABM do not follow the same simulation paradigm or formalism; however, through the HLA federation, these two distinct and spatially distributed simulation models are able to synchronize their data during run time. We used a case study building to illustrate the applicability of the federation for determining optimum feedback frequency to building occupants. This framework provides the basic loose coupling strategy that allows us to integrate EMCS data sources with running simulation models to realize on-line simulation.

\section{ON-LINE SIMULATION OF BUILDING ENERGY PROCESSES}

\subsection{On-Line Simulation}

Traditional simulation models have limited use during a system's operation phase, and are thus often called "throw away models" (Rao et al. 2008). In building energy simulation, since the models and the real building processes are not coupled (in most cases, the real buildings may not exist), such models are in- 
itialized either in an empty state or in a state obtained after running the models through a warm-up period. In the second case, even if a real building exists, the initial state of the model does not correspond exactly to the real building state at a given moment. As the models are disconnected from the real processes, this type of simulation can be referred to as 'Off-Line Simulation' (Mirdamadi et al. 2007).

On the other hand, in an 'On-Line Simulation,' the model has a direct and persistent connection with the real process (Rao et al. 2008). The current state variables monitored from a real process are used to initialize the simulation. Based on the simulation results, a new corrective or policy decision is made and immediately implemented in the real process. The real process can then continue to operate until the next disruptive or scheduled event occurs, at which time the steps will repeat, thereby realizing an interactive control mechanism. The proposed concept is graphically described as a flowchart in Figure 1. In the context of this research, this involves the integration of sensors and meters installed in buildings as part of an EMCS with an "off-line" simulation to enable 'On-Line Simulation'.

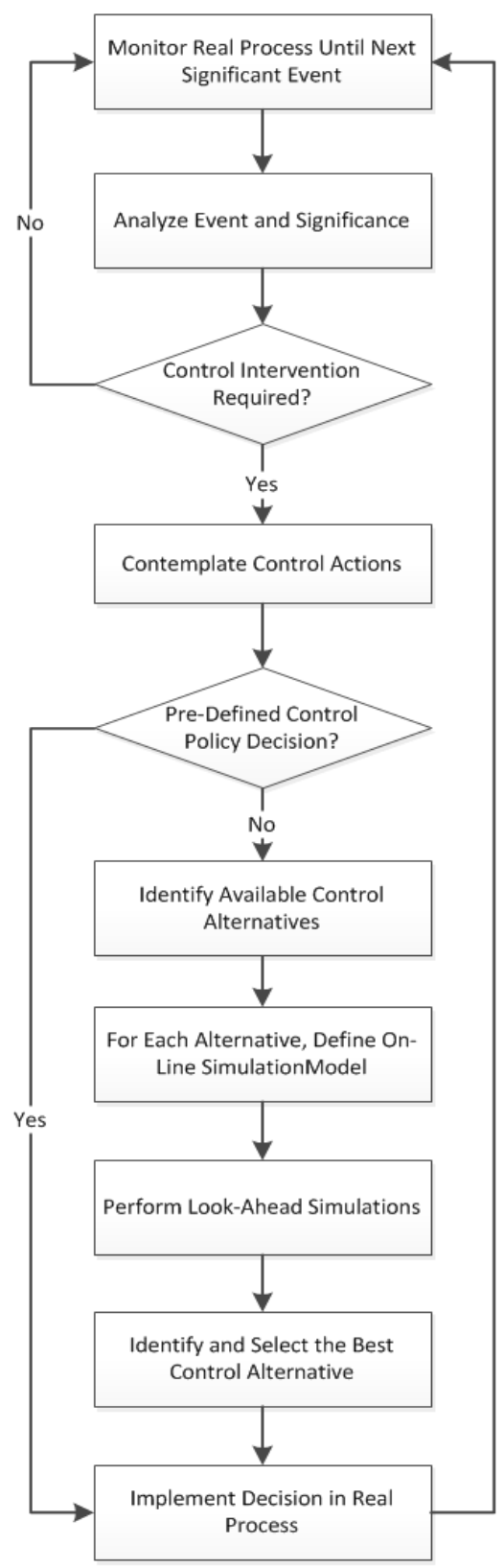

Figure 1: Principle of real-time control with on-line simulation 
On-line simulation can allow facility managers to understand/mitigate problems in a dynamic system on a real-time basis (i.e. as they occur). They can also anticipate unexpected problems and can suggest means of improving system reactivity (Rao et al. 2008). In building energy analysis, on-line simulation can allow decision-makers to select the best alternative among scheduling heuristics or loading rules during operation of an HVAC system, evaluate candidate "what-if" scenarios for user comfort in response to contemplated actions, and predict building energy performance at any given time. In this case, sensors, which may be part of a the building EMCS, will automatically update the energy model with information related to indoor/outdoor temperature, indoor/outdoor humidity, occupancy, time of the day and $\mathrm{CO} 2 \mathrm{lev}-$ els in certain parts of the building. The building manager can use this information to predict energy required HVAC system and determine if corrective actions are necessary to reduce the energy use profile.

The basic idea behind on-line simulation is that a decision-maker will avoid taking a controlling action based on pre-defined policy, and will instead run several near-future simulations for a small number of alternative actions (or decisions), and select the option that optimizes the objective function relevant to that context. This is graphically depicted in Figure 2. The goal is thus to obtain a useful anticipated future result that can be implemented in the real process within a time frame in which the implemented action is still useful. The duration of such a time frame is context specific (e.g., changes in user comfort parameters may be required immediately, or at a future scheduled time). The challenge in this regard is thus to create a mechanism that allows a controller to interactively identify the number of feasible alternatives to be simulated and the simulation duration such that it allows a reaction on the physical system in real-time without interfering with the current building operation. For example, based on historical data from sensors and real time data collected at time decision is ot be made, the facility manager would be able to use the simulation (e.g., computational fluid dynamics-CFD) to determine appropriate time to switch building from mechanical to natural ventilation mode (e.g., Menassa et al. $2013 \mathrm{~b}$; Menassa et al. 2013c). The alternatives would be to decide whether to switch to natural ventilation when energy savings exceed a certain threshold, when there is sufficient evidence to show that natural ventilation can be utilized for a minimum time period (e.g., at least 3 hours) or maintain natural ventilation as long as $\mathrm{CO} 2$ level in the ventilated space are within acceptable limits.

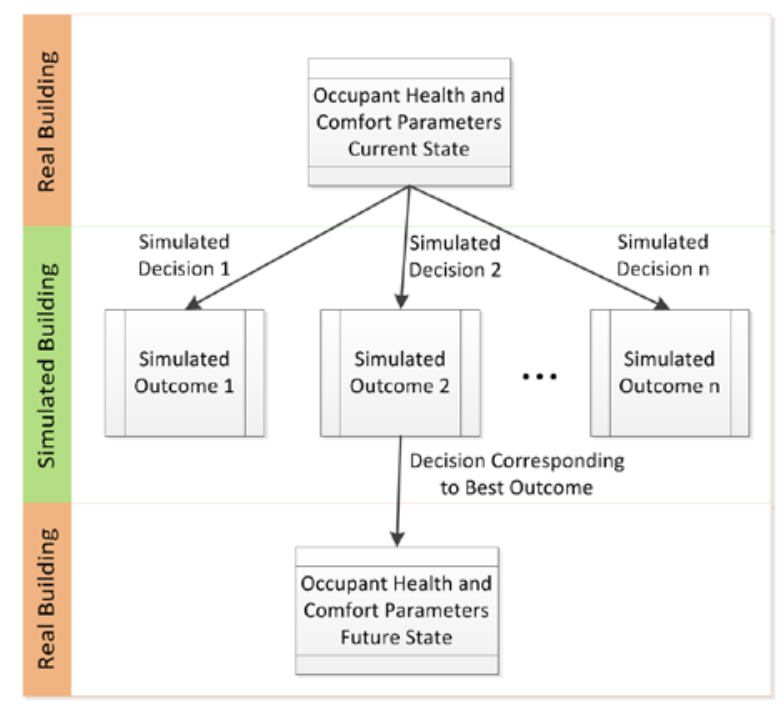

Figure 2: Arriving at optimal decision with on-line simulation

The simulation model must be sufficiently close to reality and contain variables that can be associated with the state of the real process. It is therefore necessary to have an on-line connection or coupling with the real process so that any implemented monitoring technology can interface with the model and automatically initialize the state variables before simulating scenarios in the near future. Sensors and meters 
installed in a building can be readily encapsulated by a data collection software process to enable federated on-line simulation. The challenges to achieve this are related to the selection, extraction, and mapping of the right data at the required time and frequency to perform on-line building simulations.

In designing any simulation experiment, the "depth" indicates the look-ahead duration and the "width" indicates the number of simulations to run for each alternative in order to achieve a desired confidence interval (Dalal et al. 2003). The challenge in this regard is thus to create a simulation framework that is scalable and can interactively guide a controller in selecting appropriate values for the depth and width of the simulation experiments at any decision point.

\subsection{Implementation of On-Line Simulation Framework}

The implementation of a real-time control framework using on-line simulation involves the following steps: monitoring, data-collection, simulation, decision, and implementation. In order to experiment with the proposed idea and evaluate its effectiveness in serving as a responsive and objective control mechanism for building energy analysis, methods to integrate EMCS components into the simulation are needed. Figure 3 presents the developed architecture highlighting on-line simulation of building energy systems as the key enabled cyberinfrastructure capability.

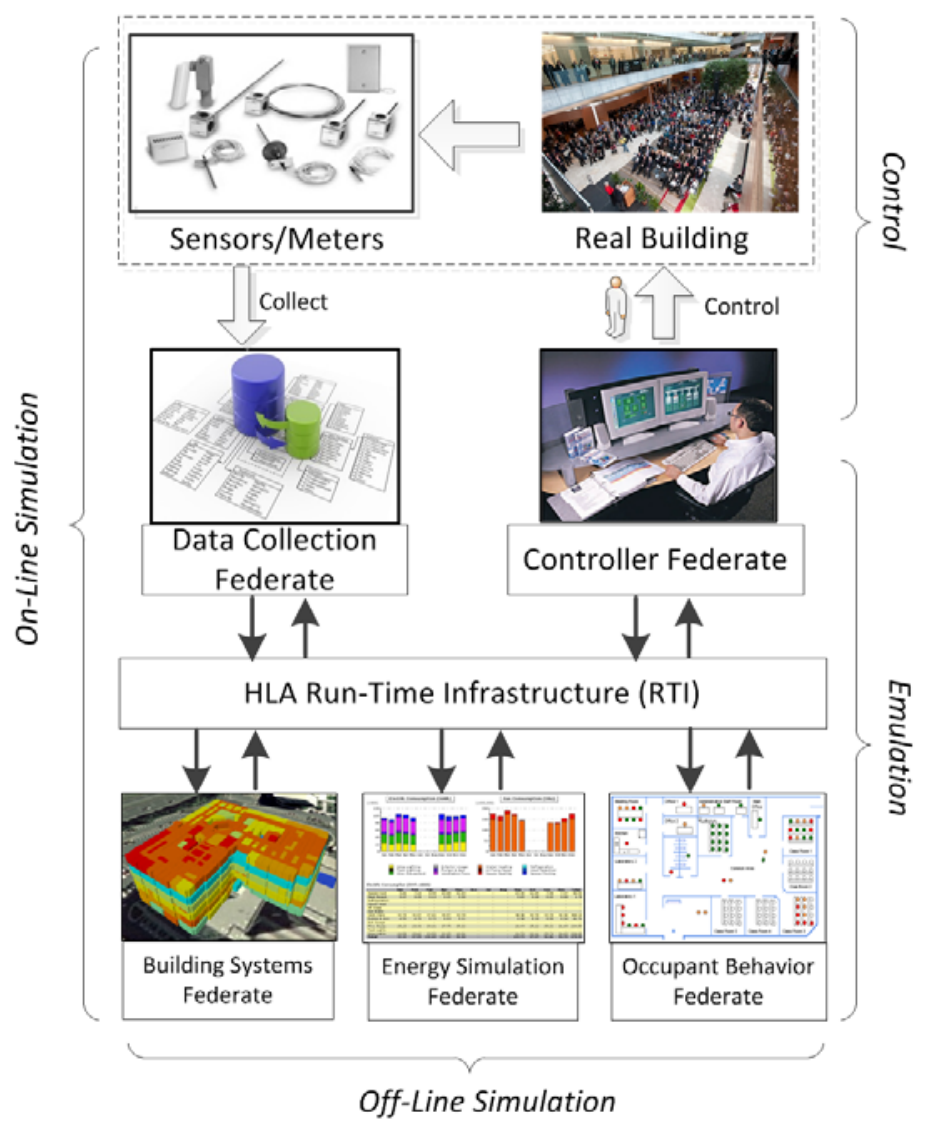

Figure 3: Implementation of on-line simulation framework

\section{VALIDATION SCHEME}

The purpose of the validation experiments under this section is to verify that the federated simulation numbers are consistent with the actual electricity and gas consumption levels at a case study building located on the University of Wisconsin - Madison campus. Initial data are collected to develop the energy 


\section{Kamat, Menassa, and Lee}

model using eQuest. The objective of this phase is to establish an accredited model to a level where decision makers accept it as a surrogate to the real building system for purposes of experimenting. This phase is divided into two main validation experiments with the purpose of verifying the original research hypothesis that discrepancy occurs between predicted and actual energy use in buildings because existing energy models are oversimplified, and do not consider or model all the interconnected processes that eventually determine energy consumption in real buildings.

\subsubsection{Historical Validity Check}

In this phase, monthly energy use data collected for the case study building during 2010, 2011 and 2012 will be used to validate the model's energy predictions versus the original estimates obtained for the building from using the eQuest model alone. More specifically, the eQuest model provides the baseline weekly estimate of the energy consumption in the building denoted as $E_{b}$. The federated on-line simulation model is then be used to determine predicted monthly energy for the building. .This new prediction will be denoted by $E_{p}$. Finally, the measured actual energy use in the building from meter data will be compiled into $E_{a}$ for each week as well. Using this information, two values for difference between actual and predicted energy use will be calculated as $\Delta 1=E_{a}-E_{b}$ and $\Delta 2=E_{a}-E_{p}$ respectively for each week in 2010, 2011 and 2012. Given the research hypothesis that the federated simulation model of the building provides a better representation of the actual building energy use, we expect that $\Delta 2$ will be significantly less than $\Delta l$ at $95 \%$ confidence level using the pooled variance t-test. If this is the case, then we consider the federated simulation model to be validated as it closely represents real word scenario. This makes the federated simulation model ready for use as an emulator to test building systems as described in the second validation experiment below. This level of model validity, which will also be used for subsequent validation experiments, is acceptable for energy simulation calibration (US DOE 2008 and 2002; ASHRAE 2007b; Yoon at al. 2003; Haberl and Bou-Saada 1998; Kaplan 1992; Pratt 1990).

\subsubsection{Future Validity Check}

This step will use the model to predict the energy consumption levels at the case study building for a short period of time, and then collect actual energy use data to test the model's estimated numbers. The federated simulation model will be run to estimate the energy consumption levels at the case study building on a weekly basis for 3 months. The estimated energy consumption per week is denoted by $E_{p w}$. After three months, actual energy use for the building on a weekly basis, denoted by $E_{a w}$, is recorded. If the difference between these values is less than $10 \%$ at $95 \%$ confidence level, then the federated simulation model is also validated for future prediction of building behavior and energy consumption.

\section{CONCLUSION}

Despite significant advances in energy simulation, energy management and control systems (EMCS), and occupancy interventions, buildings continue to use more than $40 \%$ of the nation's total primary energy and $70 \%$ of the generated electricity. One important limitation of existing energy analysis and control tools is that they are developed for a specific purpose and phase of the building life-cycle, which prevents their individual benefits from being collectively exploited to accurately predict, monitor, and improve energy efficiency in buildings. This paper presented an energy simulation framework and the software infrastructure that supports the creation of on-line simulations to model complex behaviors that occur at the building-occupant-energy-controller interface in buildings. On-line simulation capabilities can be realized by coupling models to an EMCS interface. The paper argued that on-line simulation can provide decision makers in buildings with a reliable energy model to test different technical and behavioral interventions, and accurately predict building performance, compared to the results obtained with existing off-line simulation models. 
Kamat, Menassa, and Lee

\section{ACKNOWLEDGMENTS}

The authors would like to acknowledge the National Science Foundation (NSF) for partially supporting this research via grants CMMI-BRIGE 1125478 and CBET 1132734. Any opinions and findings in this paper are those of the authors and do not necessarily represent those of the NSF.

\section{REFERENCES}

Abraham, M. and Nguyen,N. (2004) "Green engineering: Defining the Principles." Environmental Progress, 22(4), 233-236.

Abrahamse, W., Steg, L., Vlek, C., and Rothengatter, T. (2005). "A review of intervention studies aimed at household energy conservation." Journal of Environmental Psychology, 25(3), 273-291.

Anderson, K., Lee, S. and Menassa, C. (2013). "Agent-based Model of Impact of Social Networks on Change in Building Occupant Behavior Energy Use.” Journal of Computing in Civil Engineering Special Issue on Computational Approaches to Understand and Reduce Energy Consumption in the Built Environment, ASCE - Tentatively accepted.

ASHRAE, (2007b). Guideline 14: Measurement of Energy and Demand Savings (2007).

Azar, E., and Menassa, C. C. (2012). "Agent-Based Modeling of Occupants' Impact on Energy Use in Commercial Buildings." Journal of Computing in Civil Engineering, ASCE, 26(4), 506.

Banks, J., J. S. Carson, B. L. Nelson, and D. M. Nicol. 2000. Discrete-Event System Simulation. 3rd ed. Upper Saddle River, New Jersey: Prentice-Hall, Inc.

Brooks, C., Lee, E. A., Liu, X., Neuendorffer, S., Zhao, Y. and Zheng,H. (2007). "Ptolemy II - heterogeneous concurrent modeling and design in Java." Technical report No. UCB/EECS-2007-7, Berkeley, CA: University of California at Berkeley.

Capehart, B., Turner, W., Kennedy, W. (2003). Guide to energy management.4th ed. The Fairmont Press, Inc, Lilburn, Georgia.

Cheng, R. C. H. 1994. "Selecting Input Models." In Proceedings of the 1994 Winter Simulation Conference, Edited by J. D. Tew, S. Manivannan, D. A. Sadowski, and A. F. Seila, 184-191. Piscataway, New Jersey: Institute of Electrical and Electronics Engineers, Inc.

Dell'lsola, A. J. and Kirk,S. J.(2003). "Life Cycle Costing of Facilities". Reed Construction Data, Kingston, MA.

Doukas, H., Nychtis, C. and Psarras, J. (2009). "Assessing energy saving measures in buildings through an intelligent decision support model." Building and Environment, 44(2009), 290-298.

EIA (2012). "U.S. Energy Information Administration Glossary." Energy Information Administration. Available at: http://www.eia.gov/tools/glossary/index.cfm, last accessed September 2012.

EnergyPlus (2009a). "Input/Output Reference: The Encyclopedic Reference to EnergyPlus Input and Output". The Board of Trustees of the University of Illinois and the Regents of the University of California through the Ernest Orlando Lawrence Berkeley National Laboratory. Available at: http://apps1.eere.energy.gov/buildings/energyplus/pdfs/inputoutputreference.pdf, last accessed January $21,2010$.

eQuest (2009). "Introductory Tutorial, version 3.63". http://doe2.com/download/equest/eQ-v363_Introductory-Tutorial.pdf, last accessed July 1, 2011.

Goldman, C., Reid, M., Levy R. and Silverstein, A. (2010). "Coordination of Energy Efficiency and Demand Response." Environmental Energy Technologies Division, Ernest Orlando Lawrence Berkeley National Laboratory, LBNL-3044E.

Herrmann, R. K. (2005). "Building Automation and LEED Credits." ASHRAE Journal, 47 (9), 10-17.

Haberl, J. and Bou-Saada, T. (1998). "Procedures for calibrating hourly simulation models to measured building energy and environmental data." Journal of solar energy engineering. 120 (1998) 193-205.

Jiang, Z., Xia, J. and Jiang, Y. (2009). “An information sharing building automation system.” Intelligent Buildings International, Earthscan, 1 (2009), 195-208. 
Kaplan, M., J. Mcferran, J. Jansen, and R. Pratt. "Reconciliation of a DOE2.1c model with monitored end-use data from a small office building" ASHRAE Transactions 96(1), 1992.

Katipamula, S. and Brambley, M. R. (2005a). "Methods for Fault Detection, Diagnostics, and Prognostics for Building Systems-A Review, Part I." International Journal of HVAC\&R Research, 11(1), 3-25.

Katipamula, S. and Brambley, M. R. (2005b). "Methods for Fault Detection, Diagnostics, and Prognostics for Building Systems-A Review, Part II.” International Journal of HVAC\&R Research, 11(2), 169187.

Kim, H., and Anderson, K. (2012). "Energy Modeling System using Building Information Modeling (BIM) Open Standards". Journal of Computing in Civil Engineering, in press. Available at: http://ascelibrary.org/doi/pdf/10.1061/\%28ASCE\%29CP.1943-5487.0000215, last accessed October 19, 2012.

Meier, A., Aragon, C., Hurwitz, B., Peffer, T. and Pritoni, M. (2010). "How People Actually use Thermostats." Washington, D.C.: American Council for an Energy-Efficient Economy.

Lee, S. U., Painter, F. L. and Claridge, D. E. (2007). "Whole-building commercial HVAC system simulation for use in energy consumption fault detection." ASHRAE Transactions, 113(2), 52-61.

Lowry, G., (2002). "Factors affecting the success of building management system installations." Building Services Engineering Research \& Technology, 23(1), 57-66.

Menassa, C., Kamat, V., Lee, S., Azar, A., Feng, C. and Anderson, K. (2013a). "A Conceptual Framework to Optimize Building Energy Consumption by Coupling Distributed Energy Simulation and Occupancy Models." Journal of Computing in Civil Engineering -Special Issue on Computational Approaches to Understand and Reduce Energy Consumption in the Built Environment, ASCE Tentatively accepted.

Menassa, C., Taylor, N., and Nelson, J. (2013b). "Optimizing Hybrid Ventilation in Public Spaces of Complex Buildings - A Case Study of the Wisconsin Institutes for Discovery." Building and Environment, ELSEVIER Volume 61 (2013), 57-68.

Menassa, C. Taylor, N., and Nelson, J. (2013c). "A Framework for Automated Control and Commissioning of Hybrid Ventilation Systems in Complex Buildings." Automation in Construction, ELSEVIER. Volume 30 (2013), 94-103.

Menassa, C., Mangasarian, S., El Asmar, M. And Kirar, C. (2012). "Energy Consumption Evaluation of United States Navy LEED Certified Buildings." Journal of Performance of Constructed Facilities, American Society of Civil Engineers, 26 (1), 46-53.

Mirdamadi, S., F. Fontanili and L. Dupont (2007). "Discrete event simulation-based real-time shop floor control", Proc. 21 st Eur. Conf. Modelling and Simulation (ECMS 2007), pp.235 - 240.

Pang, X., Wetter, M., Bhattacharya, P. and Haves, P. (2012). "A framework for simulation-based realtime whole building performance assessment." Building and Environment, 54 (2012) 100-108.

Peschiera, G. and Taylor, J. (2012). "The Impact of Peer Network Position on Electricity Consumption in Building Occupant Networks Utilizing Energy Feedback Systems," Energy and Buildings, 49 (June 2012), 584-590.

Peschiera, G., Taylor, J., and Siegel, J. (2010). "Response-Relapse Patterns of Building Occupant Electricity Consumption Following Exposure to Personal, Contextualized and Occupant Peer Network Utilization Data," Energy and Buildings, 42(8): 1329-1336.

Pratt, R.G., " Errors in audit predictions of commercial lighting and equipment loads and their impacts on heating and cooling estimates", ASHRAE Transactions 90-11-2, 1990.

Rao, Y., He, F., Shao, X., Zhang, C. (2008). "On-line simulation for shop floor control in manufacturing execution system”, In: Xiong, C.-H., Liu, H., Huang, Y., Xiong, Y.L. (eds.) ICIRA 2008. LNCS (LNAI), vol. 5315, pp. 141-150. Springer, Heidelberg.

Samuelson, H. W., Lantz, A. and Reinhart, C. (2011). "Identifying Non-Technical Barriers to Energy Model Sharing and Reuse." Proceedings of Building Simulation 2011, Sydney, Australia. Available at: http://dosen.narotama.ac.id/wp-content/uploads/2012/03/Identifying-non-technical-barriers-toenergy-model-sharing-and-reuse.pdf, last accessed January 2013. 
Schein, J., Bushby, S. T., Castro N. S. and House, J. M. (2006). "A rule-based fault detection method for air handling units." Energy and Buildings, 38 (2006), 1485-1492.

Soebarto, V. I. and Williamson, T.J. (2001). Multi-criteria Assessment of Building Performance: Theory and Implementation. Building and Environment, Elsevier, 36(6):681-690.

Široky', J., Oldewurtel, F., Cigler, J. and Prívara, S. (2011). "Experimental analysis of model predictive control for an energy efficient building heating system." Applied Energy, 88 (2011), 3079-3087.

Staats, H., Harland, P., and Wilke, H. A. M. (2004). "Effecting Durable Change: A Team Approach to Improve Environmental Behavior in the Household." Environment and Behavior, Sage Publications, 36(3), 341-367.

Staats, H., van Leeuwen, E., and Wit, A. (2000). "A Longitudinal Study of Informational Interventions to Save Energy in an Office Building." Journal of Applied Behavior Analysis, Society for the Experimental Analysis of Behavior, 33(1), 101-104.

Wetter, M. (2011). "Co-simulation of building energy and control systems with the Building Controls Virtual Test Bed." Journal of Building Performance Simulation, 4(3), 185-203.

Wu, S. and Sun, S. W. (2010). "Multilevel fault detection and diagnosis on office building HVAC systems." 2010 ACEEE Summer Study on Energy Efficiency in Buildings, American Council for energy Efficient Economy, 3: 362-373.

United Nations Environment Programme. (2007). "Buildings Can Play Key Role in Combating Climate Change." SBCI-Sustainable Construction and Building Initiative, Available at http://www.unep.org/Documents.Multilingual/Default.Print.asp, last accessed January 2013.

US Environmental Protection Agency - (EPA) (2012). "Guidelines for Energy Management." http://www.energystar.gov/index.cfm?c=guidelines.download_guidelines, last accessed April 2012.

US Environmental Protection Agency (EPA). (2010). ENERGY STAR ${ }^{\circledR}$ and Other Climate Protection Partnerships - 2010 Annual Report 2010 ANNUAL REPORT.

US Department of Energy (DOE) (2002). International Performance Measurement \& Verification Protocol: Concepts and Options for Determining Energy and Water Savings Vol. I (2002).

US Department of Energy (DOE) (2008). M\&V Guidelines: Measurement and Verification for Federal Projects (2008).

Yoon, J., Lee, E.J. and Claridge, D. (2003). "Calibration procedure for energy performance simulation of a commercial building." Journal of solar energy engineering. 125 (2003), 251-257.

Yudelson, J. (2010). “Greening Existing Buildings.” McGraw Hill - A Green Source Book, New York.

\section{AUTHOR BIOGRAPHIES}

VINEET R. KAMAT is an Associate Professor at the University of Michigan. He received a Ph.D. in Civil Engineering at Virginia Tech in 2003. His primary research interests include virtual and augmented reality, simulation, information technology, and their applications in Civil Engineering. His email address isvkamat@umich.edu and his web page is located at http://pathfinder.engin.umich.edu.

CAROL C. MENASSA is an Assistant Professor at the University of Michigan. She received her Ph.D. in Civil Engineering from the University of Illinois at Urbana-Champaign. Her main research area is building energy modeling and simulation including developing occupancy energy use behavioral models. Her email ismenassa@umich.edu and her web page is http://sitemaker.umich.edu/menassa/.

SANGHYUN LEE is an Assistant Professor at the University of Michigan. He earned a Ph.D. in Construction Management and Information Technology from MIT. His main research interest is the understanding and management of construction dynamics through the design and development of mechanisms, models, and systems that enhance proactive management of mega construction projects. His e-mail is shdpm@umich.edu and his web page is http://sitemaker.umich.edu/dpm/. 